\title{
Evaluation of serum aminotransaminases and bilirubin in different treatment regimens for chronic hepatitis $\mathrm{C}$ virus
}

\author{
Fagr B. Bazeed ${ }^{1}$, Elsherbeny H. Elsayed ${ }^{2}$, Amani A. Abd El-Aziz ${ }^{2}$ \\ ${ }^{1}$ (Department of Biochemistry, College of Medicine/ Mansoura University, Egypt) \\ ${ }_{2}^{2}$ (Department of Chemistry, College of Science/ Port Said University, Egypt)
}

\begin{abstract}
Hepatitis C virus (HCV) affects more than 180 million people worldwide and it is the leading cause of chronic liver disease. The aim of this study is to detect liver enzymes and bilirubin levels before and after different anti viral therapies in Egyptian chronic hepatitis $C$ infected patients. One hundred and fifty patients with chronic $H C V$ infection who have anti HCV antibodies detected by ELISA were selected to undergo Real-Time polymerase chain reaction (RT-PCR); of them 30 blood samples were positive for HCV antibodies and negative for HCV RNA (control group I) and 120 blood samples were positive for HCV antibodies and positive for HCV RNA (diseased group II) which is subdivided into four groups according to the received treatment; interferon and ribavirin (group IIa), interferon, sofosbuvir and ribavirin (group IIb), sofosbuvir and ribavirin (group IIc) and herbal therapy (group IId). Results revealed; after treatment there was a statistical significant reduction in the mean values of ALT in group IIa, group IIb and group IIc (mean: 38.00, 45.5 and 36.00 U/L respectively; $P<0.0001)$ while, group IId showed a non significant decrease in ALT levels after treatment (mean: 45.0 U/L; P>0.05). AST levels showed a non significant increase after treatment in group II (mean: $43.7 \mathrm{U} / \mathrm{L} ; \mathrm{P}>0.05$ ), a non significant decrease in group IIb and group IId (mean: 40.03 and 39.80 U/L respectively; $P>0.05$ ) and an extremely significant decrease after treatment in group IIc (mean: $28.30 \mathrm{U} / \mathrm{L} ; P<0.0001$ ). Bilirubin levels showed a non significant decrease after treatment in group IIa (mean: $0.763 \mathrm{mg} / \mathrm{dL} ; \mathrm{P}>0.05$ ), a non significant increase after treatment in group IIb (mean: $0.811 \mathrm{mg} / \mathrm{dL} ; P>0.05$ ) and an extremely significant increase in group IIc (mean: $1.05 \mathrm{mg} / \mathrm{dL}$; $P<$ 0.0001 ) while there was no significant difference in serum bilirubin levels in group IId after treatment (mean: $0.901 \mathrm{mg} / \mathrm{dL} ; P>0.05$ ). In conclusion, Serum ALT is a normal value after all treatment regimens included in our study; serum AST is slightly elevated in combination therapy of pegylated interferon plus ribavirin while serum bilirubin is highly elevated in case of sofosbuvir dual therapy than sofosbuvir trible therapy.
\end{abstract}

Key words: Hepatitis C virus, liver enzymes, bilirubin, Pegylated interferon, Sofosbuvir, Herbal therapy.

\section{Introduction}

Hepatitis $\mathrm{C}$ virus $(\mathrm{HCV})$ represents a major health problem worldwide. $\mathrm{HCV}$ patients are at risk of progressive liver disease which favors the generation of long term complications such as cirrhosis, end stage liver disease and hepatocellular carcinoma [1]. Egypt has one of the highest prevalence of hepatitis $\mathrm{C}$ in the world. HCV genotype 4 is the most common strain in Egypt followed by HCV genotype 1 ( $90 \%$ and $10 \%$ respectively). The goal of treatment of chronic hepatitis $\mathrm{C}$ is to prevent complications of hepatitis $\mathrm{C}$ infection; this is principally sought by eradication of the infection [2]. Accordingly, treatment is aimed to achieve a virological response, defined as the absence of hepatitis C virus RNA in serum by a sensitive test at the end of treatment and 6 months later (sustained virological response (SVR)). The most common treatments for chronic hepatitis $\mathrm{C}$ are interferon-based therapies given with or without some co-intervention (e.g. ribavirin) $[3,4]$. Recently in 2013, FDA approved SOVALDI (Sofosbuvir) tablets for the treatment of chronic hepatitis C (CHC) infection as a component of a combination antiviral trible treatment regimen (sofosbuvir, interferon and ribavirin) or antiviral dual treatment regimen (sofosbuvir, and ribavirin) where; Sovaldi is the first drug that has demonstrated safety and efficacy to treat certain types of $\mathrm{HCV}$ infection without the need for co-administration of interferon, and is the second drug approved by the FDA to treat chronic HCV infection [5]. Furthermore, few treatment options exist for non responders, non eligible patients, or patients who progress to develop hepatic failure and/or liver cancer. As a result, many patients worldwide have turned to complementary and alternative medicine (CAM) and to herbal medicine in particular. Laboratory liver tests are broadly defined as tests useful in the evaluation of treatment of patients with hepatic dysfunction. The liver carries out metabolism of carbohydrate, protein and fats. Some of the enzymes and the end products of the metabolic pathway which are very sensitive for the abnormality occurred may be considered as biochemical marker of liver dysfunction. Some of the biochemical markers such as serum bilirubin, alanine amino transferase, aspartate amino transferase; are considered in this article where, an isolated or conjugated alteration of biochemical markers in patients can challenge the clinicians during the diagnosis of disease related to liver directly or with some other organs. Consequently; this study aims to assess the distribution of serum aminotransferases and serum bilirubin 
in chronic hepatitis $\mathrm{C}$ patients, and to evaluate the effect of antiviral treatments on these liver biomarkers. Furthermore, we compared these treatments according to SVR after treatment completion.

\section{Materials and methods}

One hundred and fifty (150) HCV out patients aged from 25 to 57 years attending the medical outpatient clinics of General Authority of Health Insurance hospital, Mansoura, Egypt, participated in the study. These were divided into a group of 30 patients who were positive for HCV antibodies and negative for HCV RNA (control group I) and a group of 120 patients who were positive for HCV antibodies and positive for HCV RNA (diseased group II). The diseased group is subdivided into four groups according to the received treatment; interferon and ribavirin group for 48 weeks (group IIa $n=30$ ), sofosbuvir, interferon and ribavirin group for 12 weeks (group IIb $n=30$ ), sofosbuvir and ribavirin group for 24 weeks (group IIc $n=30$ ) and finally herbal group for 24 weeks (group IId $\mathrm{n}=30$ ).

The enzyme-linked immunosorbent assay (ELISA) commercial kit (Micro LISA HCV Ab; Amgenix, USA) was used for detecting anti- HCV Abs by Voller technique [6]. Serum HCV viral RNA was extracted using the QIAamp viral RNA mini kit (Qiagen, CA, USA). The extract was subjected to a quantitative HCV viral evaluation by real-time PCR according to the procedures in the instruction manual of the artus ${ }^{\circ}$ HCV RG RT-PCR kit (Qiagen) performed on a Rotor gene 5 plex instrument (Qiagen). HCV genotyping was performed on HCV-RNA-positive samples, using the VERSANT HCV LiPA 2.0 (Inno-Lipa HCV; Innogenetics, Ghent, Belgium). However, HCV genotype 4 was the common genotype in the tested cases. Blood samples were obtained at recruitment (non-fasting) and measured at routine hospital laboratories for the following parameters: alanine amino transferase (ALT), aspartate amino transferase (AST), and total bilirubin. Serum aminotransferase enzymes (ALT, AST) were determined by Ritman method [7] and total bilirubin by the method of Walters [8] using an automated biochemistry analyzer (Roche/Hitachi 917 Multichannel Analyzer).

(Group IIa) patients were prescribed subcutaneous pegylated IFN- $\alpha 2$ a (Reiferon Retard Vials, MINAPHARM, 10th of Ramadan, Egypt) $160 \mu \mathrm{g}$ once weekly and oral ribavirin (MINAPHARM) 1000 or 1200 mg daily (1000 mg for those less than $75 \mathrm{~kg}$ body weight and $1200 \mathrm{mg}$ for those more than $75 \mathrm{~kg}$ ) for 48 weeks, patients in (group IIb) received subcutaneous pegylated IFN- $\alpha 2 \mathrm{a}$, sofosbuvir (Gratisovir $400 \mathrm{mg}$ tablet, PHARCO, Alexandria, Egypt) and oral ribavirin for 12 weeks, (group IIc) patients received sofosbuvir $400 \mathrm{mg}$ and ribavirin for 24 weeks, additionally patients in (group IId) received the herbal mixture (Bee venom previously isolated from honeybee (Apis Mellifera), by intradermal injection according to a schedule of a starting dose of $10 \mu \mathrm{g}$ on the $1^{\text {st }}$ day, $40 \mu \mathrm{g}$ on the $3^{\text {rd }}$ day, $60 \mu \mathrm{g}$ on the $5^{\text {th }}$ day and finally a maintenance dose of $100 \mu \mathrm{g}$ weekly, $300 \mathrm{mg}$ of boswellia serrata taken orally in capsule form 3 times a day, and Yi zhu decoction formulation taken orally as pills by taking $500 \mathrm{mg}$ of pills 3 times daily for 24 weeks). Sofosbuvir taken orally, once daily with or without food. Ribavirin taken with food.

Analyses of data were done with GraphPad Prism version5 statistical programme. Quantitative data were presented as mean \pm standard deviation $(\mathrm{SD})$, and a p-value $<0.05$ was considered significant. Pearson's correlation coefficient was used to examine the presence of any correlation between the serum different biomarkers.

\subsection{Virological response}

\section{Results}

At the end of the treatment the 120 patients who were treated with the four treatment regimens included in our study were subjected to quantitative real-time PCR for HCV-RNA. Patients with a negative HCV RNA at the end of the treatment were defined as sustained virologic responders (SVR); incase of interferon and ribavirin treatment for 48 weeks (group IIa) SVR was $60 \%$ (18/30). Interferon, sofosbuvir and ribavirin treatment (group IIb) showed SVR of 83.3 (25/30). Sofosbuvir and ribavirin treatment (group IIc) showed SVR of $93.3 \%$ (28/30). In addition, group IId treated with herbal therapy showed SVR of $30 \%(9 / 30)$. The non-SVR group included non-responder patients that did not achieve undetectable HCV RNA levels during treatment, as well as patients who relapsed after completing treatment.

\subsection{Pre-treatment liver function tests}

Pretreatment liver function tests of all the studied groups are shown in (table1). Patients in all the diseased groups (group IIa, group IIb, group IIc, and group IId) showed an extremely significant increased serum transaminase (ALT, AST) levels (ALT mean: 50.00, 58.00, 53.10 and $48.00 \mathrm{U} / \mathrm{L}$ respectively, AST mean: 42.7, 44.67, 37.07, and 42.67 U/L respectively; $\mathrm{P}<0.0001$ ) than the normal control group (mean of ALT and AST: 28.2 and $26.6 \mathrm{U} / \mathrm{L}$ respectively). The patients in group IIa, group IIc and Group IId showed a significant higher total bilirubin (mean: $0.82 \mathrm{mg} / \mathrm{dl} ; \mathrm{p}<0.001,0.80 \mathrm{mg} / \mathrm{dl} ; \mathrm{P}<0.05$, and $0.90 \mathrm{mg} / \mathrm{dl} ; \mathrm{p}<0.0001$, respectively) than the control group (mean: $0.7200 \mathrm{mg} / \mathrm{dl}$ ); while group IIb showed a non significant increased total bilirubin (mean: $0.75 ; \mathrm{P}>0.05$ ) when compared with the control group. 


\subsection{Post-treatment liver function tests}

Post treatment liver function tests of all the studied groups are listed in (table 2). ALT levels showed an extremely significant decrease in group IIa, group IIb and group IIc (mean: 38.00, 45.5 and 36.00 U/L respectively; $\mathrm{P}<0.0001$ ); while group IId showed a non significant decrease in ALT levels after treatment (mean: 45.0 U/L; P>0.05). AST levels showed a non significant increase after treatment (mean: $43.7 \mathrm{U} / \mathrm{L}$; $\mathrm{P}>0.05$ ) in group IIa, a non significant decrease in group IIb and group IId (mean: 40.03 and $39.80 \mathrm{U} / \mathrm{L}$ respectively; P>0.05) and an extremely significant decrease after treatment in group IIc (mean: $28.30 \mathrm{U} / \mathrm{L} ; \mathrm{P}<$ 0.0001). Bilirubin levels showed a non significant decrease after treatment in group IIa (mean: $0.763 \mathrm{mg} / \mathrm{dL}$; $\mathrm{P}>0.05$ ), a non significant increase after treatment in group IIb (mean: $0.811 \mathrm{mg} / \mathrm{dL} ; \mathrm{P}>0.05$ ) and an extremely significant increase in group IIc (mean: $1.05 \mathrm{mg} / \mathrm{dL} ; \mathrm{P}<0.0001$ ) while there is no significant difference in serum bilirubin levels in group IId after treatment (mean: $0.901 \mathrm{mg} / \mathrm{dL} ; \mathrm{P}>0.05$ ). The \% change in ALT, AST and bilirubin levels with treatment is illustrated in fig. 1(A, B, C).

Table 1. Pretreatment liver function tests ALT, AST and Bilirubin of diseased groups compared to control group, $n=30$

\begin{tabular}{|l|l|l|l|l|l|l|}
\hline \multirow{2}{*}{ Groups } & \multicolumn{6}{|c|}{ Biomarkers } \\
\cline { 2 - 7 } & ALT (U/L) & P-value & AST (U/L) & P-value & Bilirubin (mg/L) & P-value \\
\hline Group I*** & $28.2 \pm 6.666$ & & $26.6 \pm 6.704$ & $0.7200 \pm 0.169$ & \\
\hline Group IIa** & $50 \pm 6.22^{*}$ & $\mathrm{P}<0.0001$ & $42.7 \pm 5.62^{*}$ & $\mathrm{P}<0.0001$ & $0.82 \pm 0.070^{*}$ & $\mathrm{P}<0.001$ \\
\hline Group IIb** & $58 \pm 6.49^{*}$ & $\mathrm{P}<0.0001$ & $44.7 \pm 7.28^{*}$ & $\mathrm{P}<0.0001$ & $0.75 \pm 0.064$ & $\mathrm{n}$ \\
\hline Group IIc*** & $53 \pm 5.77^{*}$ & $\mathrm{P}<0.0001$ & $37.01 \pm 5.79^{*}$ & $\mathrm{P}<0.0001$ & $0.80 \pm 0.072^{*}$ & $\mathrm{P}<0.05$ \\
\hline Group IId*** & $48 \pm 7.012^{*}$ & $\mathrm{P}<0.0001$ & $42.7 \pm 6.21^{*}$ & $\mathrm{P}<0.0001$ & $0.90 \pm 0.073^{*}$ & $\mathrm{P}<0.0001$ \\
\hline
\end{tabular}

* Extremely significant different from control group at $\mathrm{P}<0.0001$; very significant different from control group at $\mathrm{p} P<0.001$; significant different from control group at $\mathrm{P}<0.05$ using Student's test.

**Group I, control group; Group IIa, diseased group treated with IFN- $\alpha 2$ a and ribavirin; Group IIb, diseased group treated with IFN- $\alpha 2 \mathrm{a}$, sofosbuvir and ribavirin; Group IIc, diseased group treated with sofosbuvir and ribavirin; Group IId; diseased group treated with herbal therapy.

Table 2. Post-treatment levels of liver function tests (ALT, AST and Bilirubin) compared to pre-treatment levels $(n=30)$

\begin{tabular}{|c|c|c|c|c|c|c|c|c|c|}
\hline \multirow[t]{3}{*}{ Groups } & \multicolumn{9}{|c|}{ Biomarkers } \\
\hline & \multicolumn{3}{|c|}{ ALT (U/L) } & \multicolumn{3}{|c|}{ AST (U/L) } & \multicolumn{3}{|c|}{ Bilirubin (mg/L) } \\
\hline & $\begin{array}{l}\text { Pre- } \\
\text { treatment }\end{array}$ & $\begin{array}{l}\text { Post- } \\
\text { treatment }\end{array}$ & P-value & $\begin{array}{l}\text { Pre- } \\
\text { treatment }\end{array}$ & $\begin{array}{l}\text { Post- } \\
\text { treatment }\end{array}$ & P-value & $\begin{array}{l}\text { Pre- } \\
\text { treatment }\end{array}$ & $\begin{array}{l}\text { Post- } \\
\text { treatment }\end{array}$ & P-value \\
\hline $\begin{array}{l}\text { Group } \\
\text { IIa }\end{array}$ & $50 \pm 6.22$ & $38 \pm 6.22 *$ & $\mathrm{P}<0.0001$ & $42.7 \pm 5.62$ & $43.7 \pm 5.62$ & ns & $0.82 \pm 0.07$ & $0.76 \pm 0.06$ & ns \\
\hline $\begin{array}{l}\text { Group } \\
\text { IIb }\end{array}$ & $58 \pm 6.49$ & $\begin{array}{l}45.5 \pm \\
6.54 *\end{array}$ & $\mathrm{P}<0.0001$ & $44.67 \pm 7.28$ & $\begin{array}{l}40.03 \pm \\
6.30\end{array}$ & ns & $0.75 \pm 0.06$ & $0.81 \pm 0.07$ & ns \\
\hline $\begin{array}{l}\text { Group } \\
\text { IIc }\end{array}$ & $\begin{array}{l}53.10 \pm \\
5.77\end{array}$ & $36 \pm 5.60 *$ & $\mathrm{P}<0.0001$ & $\begin{array}{l}37.07 \pm \\
5.80\end{array}$ & $\begin{array}{l}28.3 \pm \\
5.73^{*}\end{array}$ & $\mathrm{P}<0.0001$ & $\begin{array}{l}0.80 \pm \\
0.071\end{array}$ & $\begin{array}{l}1.05 \pm \\
0.11^{*}\end{array}$ & $\mathrm{P}<0.0001$ \\
\hline $\begin{array}{l}\text { Group } \\
\text { IId }\end{array}$ & $48 \pm 7.012$ & $45 \pm 7.012$ & ns & $\begin{array}{l}42.67 \pm \\
6.21\end{array}$ & $39.8 \pm 6.19$ & ns & $0.90 \pm 0.07$ & $0.90 \pm 0.07$ & ns \\
\hline
\end{tabular}

* $\quad$ Extremely Significant different from pre-treatment levels at $\mathrm{P}<0.0001$.
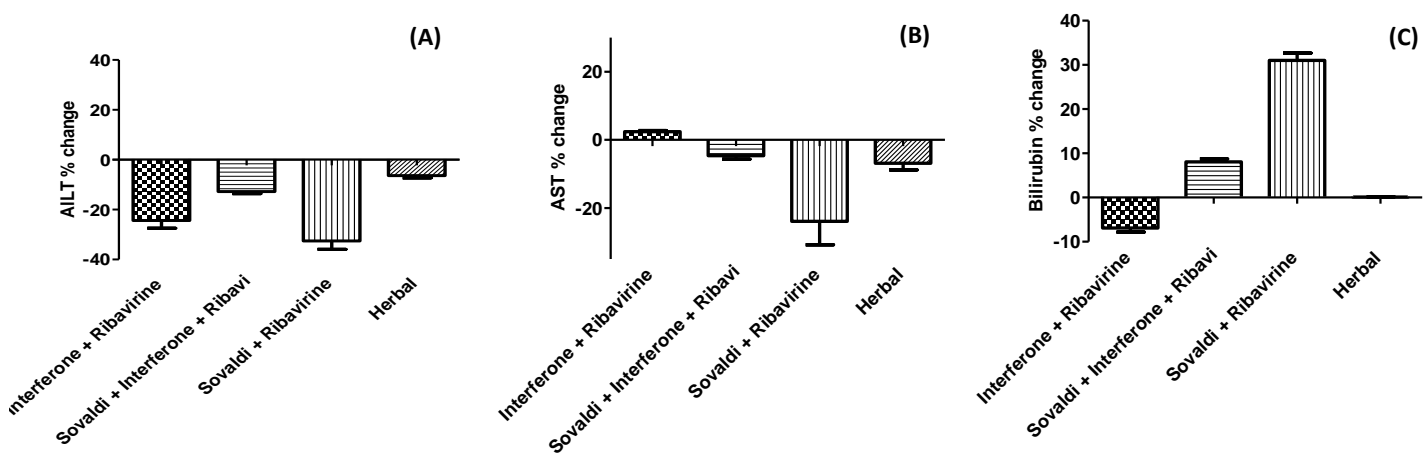

Figure 1. The $\%$ change of the evaluated serum biomarkers with treatment in all the studied groups. (a) Serum ALT \% change with treatment. (b) Serum AST \% change with treatment. (c) Serum total bilirubin \% change with treatment. 


\subsection{Correlation between serum aminotransferases and serum bilirubin}

Simple linear regression analysis showed that serum ALT levels were significantly positive correlated with serum AST in all groups IIa, IIb, IIc and IId ( $r=0.313$, $\mathrm{p}=0.015 ; \mathrm{r}=0.334, \mathrm{P}=0.009 ; \mathrm{r}=0.706, \mathrm{P}<0.0001$; $\mathrm{r}=0.810, \mathrm{P}<0.0001$; respectively). Also, serum ALT was significantly positive correlated with serum bilirubin in group IIa $(r=0.702, \mathrm{P}<0.0001)$ while; a significant negative correlation was observed between serum ALT and serum bilirubin in group IIc $(\mathrm{r}=-0.540, \mathrm{P}<0.0001)$. However, serum ALT was non significantly correlated with serum bilirubin in group IIb and group IId ( $r=-0.197, \mathrm{P}=0.1321 ; \mathrm{r}=0.0671, \mathrm{p}=0.6107$; respectively). Serum AST was significantly positive correlated with serum bilirubin in group IIa $(r=0.288, \mathrm{P}=0257)$, and they were significantly negative correlated in group IIc $(\mathrm{r}=-0.311, \mathrm{P}=0.0155)$. While, a non significant correlation was observed between serum AST and bilirubin in group IIb and group IId ( $r=-0.239, \mathrm{P}=0.0648 ; \mathrm{r}=0.061, \mathrm{p}=0.648$ respectively). Correlations between the studied serum biomarkers are listed in (table 3).

\section{Discussion}

Hepatitis $\mathrm{C}$ virus ( $\mathrm{HCV}$ ) affects approximately $3 \%$ of the world population. Egypt has one of the highest prevalence of hepatitis $\mathrm{C}$ in the world. Combination therapy using pegylated interferon alfa $2 \mathrm{a}$ or alfa $2 \mathrm{~b}$ plus ribavirin was the established standard therapy for chronic hepatitis $C[9,10]$. However, non-response to this therapy remains common and is associated with several factors. Therefore, new medications and approaches to treatment are needed. Complementary therapies are being used increasingly [11]. New regimens involving direct-acting antiviral agents (DAAs) have recently been approved for the treatment of genotype $4 \mathrm{HCV}$. One of the newly approved DAAs indicated for the treatment of genotype $4 \mathrm{HCV}$ is sofosbuvir, an oral HCV-specific NS5B nucleotide polymerase inhibitor with demonstrated clinical efficacy in patients with genotype 1 to $6 \mathrm{HCV}$ $[12,13]$. Aminotransferase enzymes are sensitive indicators of liver cell injury and helpful in recognizing acute hepatocellular diseases [14]. In this study we aimed to assess the effect of antiviral therapy on the liver enzymes aspartate aminotransferase (AST), alanine aminotransferase (ALT) and total bilirubin concentrations before and after treatment using standard methodologies. The liver function tests before treatments showed extremely significant elevations in serum ALT and AST of all the diseased groups than the normal control group. Also the serum level of bilirubin was significantly elevated in all groups when compared with the control group except group IIb showed a non significant increased total bilirubin compared to the control group. These results are in accordance with several other reports detecting the levels of biochemical markers of HCV; patient groups were higher than healthy individuals groups. Furthermore, People with chronic hepatitis $\mathrm{C}$ have abnormal serum liver enzyme levels most of the time; this occurs when liver cells are damaged, ALT and AST (proteins made by liver cells) leak out into the blood stream and the level of ALT and AST in the blood is higher than normal. But the levels can fluctuate between normal and abnormal throughout the course of the disease $[15,16]$. In addition, Levels of bilirubin in the blood go up and down in patients with hepatitis $\mathrm{C}$ where bilirubin levels are usually normal until a significant amount of liver damage has occurred [17-19]. Moreover, backward leakage or decreased excretion of the pigment results in elevation of the serum total bilirubin level in patients suffering from chronic viral hepatitis. 
$\underline{A}$

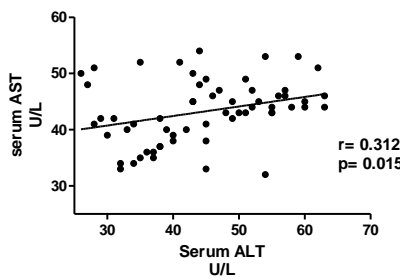

$\underline{\mathbf{D}}$

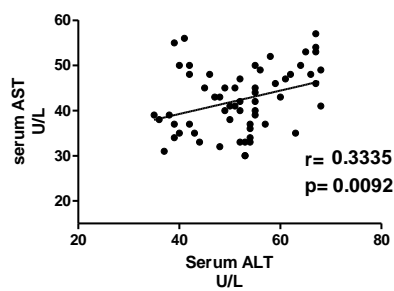

$\underline{\mathbf{G}}$

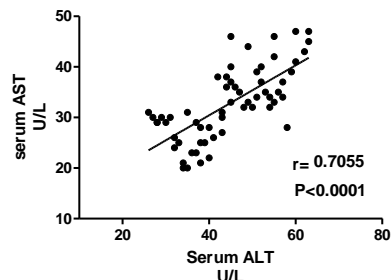

$\underline{\mathbf{J}}$

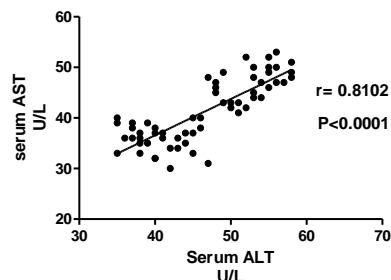

$\underline{B}$

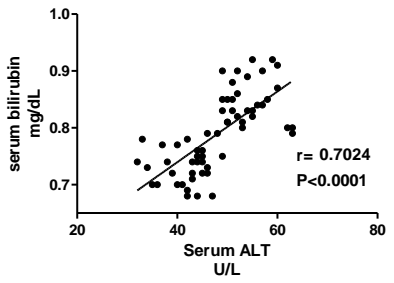

$\underline{E}$

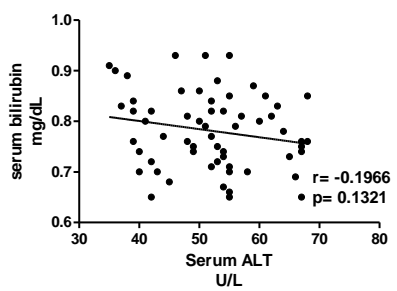

$\underline{\mathbf{H}}$

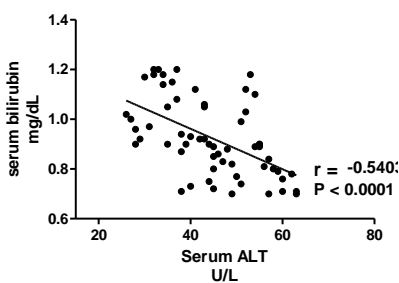

$\underline{\mathbf{K}}$

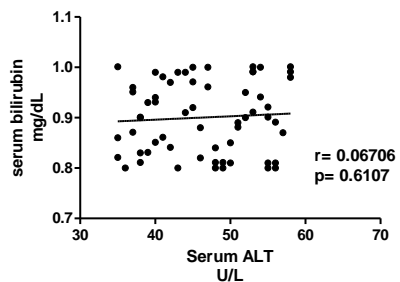

$\underline{\mathbf{C}}$

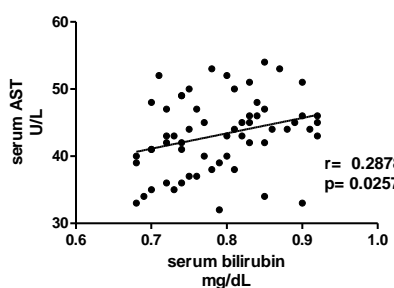

$\underline{\mathbf{F}}$

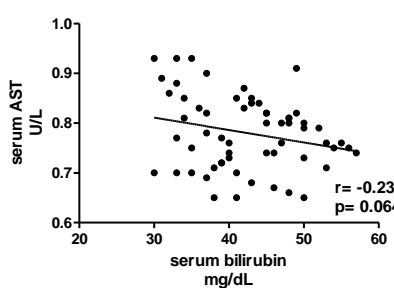

!

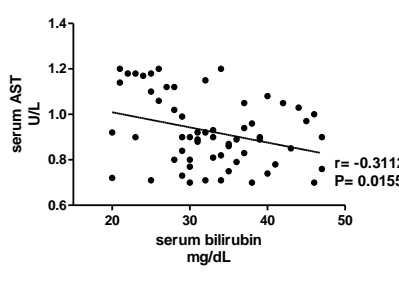

$\underline{\mathbf{L}}$

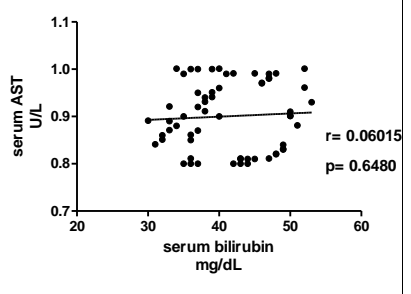

Figure 2. Correlations between serum ALT, AST, and bilirubin in all the studied groups. (A, B, C) Correlations in group IIa. (D, E, F) Correlations in group IIb. (G, H, I) Correlations in group IIc. (J, K, L) Correlations in group IId.

Table 3. Pearson's correlation between serum aminotransferases \& serum bilirubin in all the studied groups.

\begin{tabular}{|c|c|c|c|c|c|c|c|c|}
\hline \multirow[t]{2}{*}{ Parameter } & \multicolumn{2}{|c|}{ Group IIa } & \multicolumn{2}{|c|}{ Group IIb } & \multicolumn{2}{|c|}{ Group IIc } & \multicolumn{2}{|c|}{ Group IId } \\
\hline & $r$ & $P$-value & $r$ & $P$-value & $r$ & $P$-value & $r$ & $P$-value \\
\hline a) ALT \& AST & $0.313 *$ & 0.015 & $0.334 *$ & 0.009 & $0.706^{*}$ & $<0.0001$ & $0.810 *$ & $<0.0001$ \\
\hline b) ALT \& Bilirubin & $0.702 *$ & $<0.0001$ & -0.197 & $\mathrm{~ns}$ & $-0.540 *$ & $<0.0001$ & 0.0671 & ns \\
\hline c) AST \& Bilirubin & $0.288^{*}$ & 0.0257 & -0.239 & $\mathrm{~ns}$ & $-0.311 *$ & 0.0155 & 0.061 & ns \\
\hline
\end{tabular}

* Extremely significant correlation at $\mathrm{P}<0.0001$; very significant correlation at $\mathrm{p} \mathrm{P}<0.001$; significant correlation at $\mathrm{P}<0.05 \&$ non significant at $\mathrm{P}>0.05$.

Patients received combined pegylated interferon--alfa (PEG-IFN)-ribavirin therapy for 48 weeks (group IIa) showed SVR of $60 \%$ (18/30). These results agreed with many previous studies Where, Thuy et al. (2012) recorded SVR in $60 \%$ and $71 \%$ of HCV patients received (PEG-IFN)-ribavirin therapy for 24 and 48 weeks respectively [20]. Concerning the results of liver enzymes levels after treatment in the same group (group IIa); values of ALT showed a statistically reduction after treatment. These results agreed with previous studies 
$[2,21]$ which reported that HCV patients received combined PEG-IFN plus ribavirin therapy for 48 weeks experienced about 50\% reduction in the mean values of ALT. However; the median of AST in (group IIa) showed a non significant increase after treatment; this increase with normal ALT may mean that the AST is coming from a different part of the body where AST is an enzyme found in high amounts in heart muscle, liver and skeletal muscle cells. So, increased levels of AST alone do not specifically indicate liver disease [22]. Other authors reported that higher AST levels may be related to elevated serum AFP levels without HCC specifically for the non SVR group [23]. Bilirubin levels showed a non significant decrease after treatment in group IIa (but it is normal value). Another study reported that serum bilirubin levels are decreased by interferon [24].

In case of patients treated with Sofosbuvir, ribavirin and pegylated interferon for 12 weeks (group IIb); ALT and AST are normal values after treatment and this predicts a good virological response (patients in this group cured with SVR of 83.3\% (25/30); Where sofosbuvir (SOF) introduction in late 2014 in a national treatment program marked the beginning of a new era in HCV therapy in Egypt. Our results are consistent with other studies $[25,26]$ which reported high SVR rates with sofosbuvir trible therapy. There was a non significant increase in serum total bilirubin levels after treatment in this group. Poor tolerability is a major reason for avoiding interferon, but the short interferon-containing regimen in group IIb was very well-tolerated. Researchers soon discovered that most people could be cured of hepatitis $\mathrm{C}$ using all-oral regimens without interferon, which must be injected and often causes difficult side-effects. So, in our work we studied interferon free regimen of sofosbuvir plus ribavirin for 24 weeks (group IIc), we obtained the highest SVR of $93.33 \%$ (28/30). The median of ALT and AST showed a statistically reduction after treatment and this agrees with the previous results $[25,27]$ which reported a big improvement by increasing the duration of treatment with sofosbuvir plus ribavirin dual therapy for 24 weeks instead of interferon-containing therapy which most people with hepatitis $\mathrm{C}$ and health professionals seek to avoid it. Total bilirubin elevation in this group was more observed where longer duration of sofosbuvir treatment. These bilirubin elevations were not associated with transaminase elevations. Bilirubin elevations may be due to sofosbuvir which has an increasing effect on direct bilirubin causing cholestasis. Our findings are in agreement with other results which reported that total bilirubin elevation of more than $2.5 \times$ upper limit of normal was observed in no patients in the Sovaldi + PEG-IFN/RBV 12-week group and in 3\% of patients in Sovaldi + RBV 24-week group [28]. Other reports revealed that oral therapy with ribavirin causes indirect hyperbilirubinemia where ribavirin causes a dose dependent red cell hemolysis after 2 to 3 weeks of therapy. The hemolysis is accompanied by a mild increase in indirect bilirubin, which may result in total bilirubin concentrations of 1.5 to $2.5 \mathrm{mg} / \mathrm{dL}[29,30]$.

By the analysis of (group IId) treated with the herbal therapy for 24 weeks, we obtained SVR of $30 \%$ (9/30); it may need longer duration of treatment. But it showed better effects on normalization of aminotransferase levels where the median of ALT and AST after 24 weeks treatment showed normal value. Some researchers reported that the herbal mixture Yi Zhu decoction which we used in our study; has effects on clearance of HCV RNA and normalization of ALT compared with glycyrrhizin plus ribavirin [31, 32]. Also, the protective effect of Bee Venom against hepatic injury is demonstrated in other researches [33]. Furthermore, Boswellia species showed significant inhibitory activities on hepatitis C-virus (HCV) protease (PR) [34]. We found that herbal remedy used in our study had no significant effect on serum bilirubin level where there was no change in bilirubin levels after treatment.

A strong positive correlation was observed between serum ALT levels and serum AST levels in groups IIb, IIc and IId; where there was a concomitant decrease in ALT and AST levels with treatment in these groups. While group IIa showed a weak significant correlation between ALT and AST where there was a non significant elevation in post treatment AST levels in group IIa; the relationship between ALT and AST is often used as a clue to the etiology of the underlying liver disease [35]. Additionally, both ALT and AST levels were positively correlated with total bilirubin in group IIa; negatively correlated in group IIc and non significantly correlated in group IIb and group IId. The above findings pointed to the relationship between the antiviral treatment and some liver biomarkers concentration and distribution.

\section{Conclusion}

This study concluded that the interferon free regimen (sofosbuvir and ribavirin) is associated with the highest SVR of $93.33 \%$ for Egyptian HCV patients participated in our work. Moreover, the antiviral treatments included in the study have effects on normalization of serum ALT and AST. The mild increase in serum AST after treatment with interferon--alfa (PEG-IFN)-ribavirin regimen may come from other organ rather than liver or it may be related to elevated serum AFP levels. Total bilirubin levels showed an increase after sofosbuvir dual and trible therapies; and it is a side effect of sofosbuvir treatment. Herbal therapy showed no significant effect on serum bilirubin while its effect is better on normalization of serum ALT and AST.

\section{References}

[1] Spengler, U. and J. Nattermann, Immunopathogenesis in hepatitis C virus cirrhosis. Clinical science, 2007. 112(3): p. 141-155. 
[2] Al-Jiffri, O., Liver enzymes and virologic response to combined pegylated interferon-ribavirin therapy in Saudi chronic hepatitis C infected patients. Middle East J Sci Res, 2013. 13: p. 101-106.

[3] Simin, M., et al., Cochrane systematic review: pegylated interferon plus ribavirin vs. interferon plus ribavirin for chronic hepatitis C. Alimentary pharmacology \& therapeutics, 2007. 25(10): p. 1153-1162.

[4] Awad, T., et al., Pegylated interferon alpha 2a versus pegylated interferon alpha 2b for chronic hepatitis C. The Cochrane Library, 2009.

[5] Kattakuzhy, S., R. Levy, and S. Kottilil, Sofosbuvir for treatment of chronic hepatitis C. Hepatology international, 2015. 9(2): p. 161-173.

[6] Voller, A., The enzyme-linked immunosorbent assay (ELISA)(theory, technique and applications). La Ricerca in clinica e in laboratorio, 1977. 8(4): p. 289-298.

[7] Ritman, S. and S. Frankel, A colorimetric method for the determination of serum GOT and GPT. Am J Clin Pathol, 1957. 28: p. 5663.

[8] Walters, M.I. and H. Gerarde, An ultramicromethod for the determination of conjugated and total bilirubin in serum or plasma. Microchemical Journal, 1970. 15(2): p. 231-243.

[9] ZAKY, S., et al., Response to Combined Pegylated Interferon and Ribavirin among Patients with Chronic Hepatitis C in Upper Egypt. The Medical Journal of Cairo University, 2011. 79(2).

[10] Vickers, A., Complementary medicine. Bmj, 2000. 321(7262): p. 683-686.

[11] Eisenberg, D.M., et al., Trends in alternative medicine use in the United States, 1990-1997: results of a follow-up national survey. Jama, 1998. 280(18): p. 1569-1575.

[12] Lawitz, E., et al., Sofosbuvir for previously untreated chronic hepatitis C infection. New England Journal of Medicine, 2013. 368(20): p. 1878-1887.

[13] Jacobson, I.M., et al., Sofosbuvir for hepatitis C genotype 2 or 3 in patients without treatment options. New England journal of medicine, 2013. 368(20): p. 1867-1877.

[14] Guh, J.-Y., et al., Impact of decreased serum transaminase levels on the evaluation of viral hepatitis in hemodialysis patients. Nephron, 1995. 69(4): p. 459-465.

[15] Greenslade, L. and S. Sargent, Assessment of liver function and diagnostic studies. Liver Diseases: An essential guide for nurses and health care professionals, 2009: p. 15.

[16] Forns, X., et al., Identification of chronic hepatitis C patients without hepatic fibrosis by a simple predictive model. Hepatology, 2002. 36(4): p. 986-992.

[17] U_S_Department_of_Veterans_Affairs. Understanding Lab Tests: Entire Lesson. [cited 2016 5th April]; Available from: http://www.hepatitis.va.gov/patient/hcv/diagnosis/labtests-single-page.asp

[18] Sherlock, S. and J. Dooley, Diseases of the liver and biliary system. 2008: John Wiley \& Sons.

[19] El Guiniady, M., et al., Clinical and pharmacokinetic study of praziquantel in Egyptian schistosomiasis patients with and without liver cell failure. The American journal of tropical medicine and hygiene, 1994. 51(6): p. 809-818.

[20] Nguyen, M.H., et al., Higher rate of sustained virologic response in chronic hepatitis C genotype 6 treated with 48 weeks versus 24 weeks of peginterferon plus ribavirin. The American journal of gastroenterology, 2008. 103(5): p. 1131-1135.

[21] Thuy, P.T.T., et al., A randomized trial of 48 versus 24 weeks of combination pegylated interferon and ribavirin therapy in genotype 6 chronic hepatitis C. Journal of hepatology, 2012. 56(5): p. 1012-1018.

[22] Hepatitis_C_New_Drug_Research_and_Liver_Health. Lab Results 101: Liver Function Tests. [cited 2016 7th of April]; Available from: http://hepatitiscnewdrugresearch.com/liver-function-tests.html.

[23] Chen, T.M., et al., Predictors of alpha-fetoprotein elevation in patients with chronic hepatitis C, but not hepatocellular carcinoma, and its normalization after pegylated interferon alfa $2 a$-ribavirin combination therapy. Journal of gastroenterology and hepatology, 2007. 22(5): p. 669-675.

[24] Onji, M., et al., Serum unconjugated bilirubin levels are decreased by interferon. International Hepatology Communications, 1993. 1(2): p. 91-96.

[25] Doss, W., et al., Sofosbuvir plus ribavirin for treating Egyptian patients with hepatitis C genotype 4. Journal of hepatology, 2015. 63(3): p. 581-585.

[26] Esmat, G., et al. Real-life results of triple therapy with the combination of sofosbuvir-pegylated interferon-ribavirin for Egyptian patients with hepatitis C. in JOURNAL OF VIRAL HEPATITIS. 2015. WILEY-BLACKWELL 111 RIVER ST, HOBOKEN 07030-5774, NJ USA

[27] Foster, G., et al., LO5: Sofosbuvir+ peginterferon/ribavirin for 12 weeks vs sofosbuvir+ ribavirin for 16 or 24 weeks in genotype 3 $\mathrm{HCV}$ infected patients and treatment-experienced cirrhotic patients with genotype $2 \mathrm{HCV}$ : The boson study. Journal of Hepatology, 2015. 62: p. S259-S260.

[28] Drugs.com. Sovaldi Side Effects. [cited 2016 6th of April]; Available from: http://www.drugs.com/sfx/sovaldi-sideeffects.html\#refs.

[29] Zimmerman, H.J., Hepatotoxicity: the adverse effects of drugs and other chemicals on the liver. 1999: Lippincott Williams \& Wilkins.

[30] Kamar, N., et al., Ribavirin therapy inhibits viral replication on patients with chronic hepatitis E virus infection. Gastroenterology, 2010. 139(5): p. 1612-1618.

[31] Liu, J., et al., Medicinal herbs for hepatitis C virus infection: a Cochrane hepatobiliary systematic review of randomized trials. The American journal of gastroenterology, 2003. 98(3): p. 538-544.

[32] Azzam, H., et al., Natural products and chronic hepatitis C virus. Liver International, 2007. 27(1): p. 17-25.

[33] Kim, K.H., et al., The Protective Effect of Bee Venom against Ethanol-Induced Hepatic Injury via Regulation of the Mitochondria-Related Apoptotic Pathway. Basic \& clinical pharmacology \& toxicology, 2010. 107(1): p. 619-624.

[34] Alam, M., et al., A review on phytochemical and pharmacological studies of Kundur (Boswellia serrata roxb ex colebr.) —a Unani drug. Journal of Applied Pharmaceutical Science, 2012. 2(3): p. 148-156.

[35] Williams, A. and J.H. Hoofnagle, Ratio of serum aspartate to alanine aminotransferase in chronic hepatitis. Relationship to cirrhosis. Gastroenterology, 1988. 95(3): p. 734-739. 